\title{
III. Proceso productivo agrícola y desarrollo social *
}

Por Gloria GONZALEZ SALAZAR

Consideraciones generales

Dicho en forma por demás somera, lo social, en su acepción convencional más amplia, es lo concerniente a la sociedad, es decir, a lo colectivo. Desde este ángulo, tanto lo económico como todos los aspectos del cambio y del crecimiento de la sociedad son parte de

* Fuera de los textos entrecomillados, las restantes referencias a la obra examinada constituyen meros ejemplos $-y$ no todos los que cabría citarcon respecto a los comentarios expresados. No presuponen, por tanto, interpretaciones exactas de los conceptos vertidos por los autores. Por otra parte, no se ha considerado útil repetir referencias sobre temás que aquí sólo se tocan enunciativamente y que son tratados con mayor amplitud en los otros artículos. 
un proceso social global. Empero, cuando el término social se contrapone al económico, en general se alude a uno de los dos aspectos siguientes que implican una restricción en el uso del término: 1) Lo social entendido como aspectos del desarrollo que se relacionan con el bienestar humano, como por ejemplo, la elevación del nivel de vida, la mejoría en la distribución de los bienes materiales y culturales, etc., que se presupone acompañan a los aumentos de la producción derivados del desarrollo económico; 2) Lo social definido con respecto a algunas características de la estructura social y del desarrollo social, de un modo principal en relación a los cambios en la estratificación y movilidad social y a la mayor participación de la población en las distintas áreas de la vida nacional. Renglones que en su conjunto, y en similar enfoque de abstracción, se presuponen a la vez que como factores concomitantes del proceso de desarrollo, como requisitos para fortalecerlo y continuarlo.

De acuerdo con estas acepciones convencionales, la política social puede ser concebida como un proceso conjunto o integrado con la política económica, con la que no cabe establecer separaciones tajantes, o bien como recurso adicional o complementario a la segunda, o en ambas formas a la vez, con fines a prever que el crecimiento económico vaya acompañado de mejorías en las características generales de la población en el sentido antes señalado.

El problema, sin embargo, no es tan simple, en una formación socioeconómica concreta, la vida social es la manifestación directa de las relaciones económicas, lo que implica que la política pública se da en condiciones nacionales que son definidas o determinadas por las primeras. Así, en una sociedad en que existe contradicción entre los intereses sociales y los intereses privados, el desarrollo social derivado del proceso productivo tiende a reflejar dichas contradicciones, y algo similar ocurre con las medidas específicamente orientadas a introducir mejorías en las características y niveles de vida de la población, así en el monto de los recursos que en ellas se invierten, como en su sentido final.

A reserva de volver nuevamente sobre ellos, podemos utilizar los conceptos hasta aquí expresados esquemáticamente para enfrentarlos a lo que ha ocurrido en la realidad rural mexicana, ya que resultan puntos de referencia útiles para sistematizar nuestros comentarios acerca de la manera en que algunos de estos temas son tratados en la obra que nos ocupa.

Una primer cuestión es distinguir, por un lado, el sentido y logros de la política social mexicana en su acepción más amplia, es decir, como parte del proceso productivo considerado como proceso social global. Y por el otro, el carácter de dicha política en su sentido más convencional, o sea a través de medidas complementarias y más específicamente orientadas a enfrentar problemas sociales en su acepción más restringida.

Ahora bien, en numerosos lugares de la obra que examinamos aparece registrada, desde diversas perspectivas, la preocupación de los autores con respecto a los graves desequilibrios inter e intrasectoriales que exhibe el sector agrícola, con especial hincapié en las condiciones de miseria que muestra los estratos mayoritarios del mismo. Esta preocupación se expresa inclusive en diversas partes del Resumen y Conclusiones, el que termina con las siguientes expresiones:

"Es cierto que en todo proceso de desarrollo es en el sector agrícola en donde con menos celeridad se van manifestando los beneficios del crecimiento económico, pero en el caso de México el contraste podría calificarse como exagerado y apunta como elemento generador de su propio estancamiento.

"En la etapa actual del desarrollo del país, la situación de muy bajos niveles de vida en una parte mayoritaria de la población campesina no puede ya pasar desapercibida por ningún sector, pues sus implicaciones pueden afectar a todo el sistema nacional, tanto desde el punto de vista económico, como político y social.

“...El problema del campo requiere no sólo de ajustes y fortalecimiento de los distintos problemas que en su apoyo se realizan, sino de una verdadera revolución en las actitudes y políticas hacia el medio rural, que permitan cambiar la orientación que actualmente tiene su desarrollo. Este cambio, como cualquier otro, necesariamente implicará el sạcrificio de algunos sectores, pero sólo así se podrá asegurar el desarrollo económico y social futuro del país."1

Como un poco antes se indica, no obstante que México ha experimentado avances en muchos aspectos y que el sector agrícola ha cumplido con el papel que le corresponde en el proceso de desarrollo, la población campesina no ha compartido los beneficios del crecimiento económico del país en general y de este sector en particular.

Esto en nuestras palabras, equivale a afirmar que el patrón de desarrollo económico seguido en México no ha sido capaz de tradu-

\footnotetext{
1 Véase tomo III, pp. XIV-100-101. (Cursivas nuestras).
} 
cirse en la consecución de objetivos sociales derivados del proceso productivo mismo y que las medidas específicas tendientes a atenuarlo, tampoco han funcionado eficazmente. Empero, lo importante para nuestros propósitos es considerar, por una parte, algunos de los elementos que han sido utilizados por los autores para formular su diagnóstico sobre la situación prevaleciente. $\mathrm{Y}$ por el otro, evaluar, en relación a lo anterior, unos cuantos de los rasgos más significativos de las nuevas políticas propuestas por los autores. Aunque todo esto, en la inteligencia de que, sin la pretensión de agotar el tema, sólo nos ocuparemos de algunas cuestiones importantes desde el punto de vista social.

\section{Acerca del diagnóstico del problema}

Resulta innecesario repetir datos y referencias con respecto a la escasa participación del grueso de los campesinos mexicanos en los beneficios del crecimiento agrícola y del país. De la abundante información que la citada investigación ofrece, algunos de los renglones más significativos desde el punto de vistæ social, son examinados por Silvia Millán, y otros más son considerados por Ramón Martínez Escamilla y por Arturo Bonilla, desde los ángulos histórico y económico, en las correspondientes partes de este trabajo.

Como cabe esperar, la creciente concentración de la tierra y de otros recursos productivos va acompañada de una notoria e inequitativa distribución del ingreso, bajos niveles de consumo, deprimido nivel educativo. inadecuadas condiciones de habitación y vestido, carencias nutricionales y de muchas otras insuficiencias en los principales indicadores de los distintos componentes del nivel de vida Como resultado del proceso de proletarización del campesino y de la falta de oportunidad ocupacional en otros sectores, así como del crecimiento de la población rural, el subempleo en el campo va en aumento afectando a un contingente humano cada vez mayor. Todo esto ocurre, por otra parte, en un contexto en que la estructura del poder, que subordina la organización ejidal y excluye prácticamente a los minifundistas y a los jornaleros agrícolas, no es ajena, en cambio, a los empresarios agrícolas medianos y grandes, sobre todo a estos últimos, que son los únicos que en realidad se encuentran organizados políticamente y en posición de defender sus intereses. Bajo esta situación socioeconómica y política, sin olvidar que en etapas anteriores ha habido cambios significativos en el proceso de estratificación y movilidad sociales, en los últimos años éste se ve frenado como po- sibilidad en el campo mismo, y sus perspectivas a través de la emigración, también se ven limitadas ante la lenta expansión del empleo productivo en las ciudades.

No es, desde luego, en la descripción de éstos y muchos otros hechos que son considerados por los autores en lo que cabria expresar desacuerdos importantes, al menos en lo. que atañe a su efecto demostrativo de los agudos contrastes que exhibe el medio rural. A nuestro modo de ver, la debilidad del examen de estas cuestiones se deriva de que en gran medida se trabaja a un nivel de análisis en el que, tomando los hechos como dados, se les refiere a sus causas más inmediatas, sin indagar sobre las causas subyacentes que los producen.

En nuestra opinión, una cuestión básica que no es resuelta en el diagnóstico, es la de poner en claro por qué el desenvolvimiento del capitalismo mexicano se aparta del modelo de los comportamientos intersectoriales a que es referido, y por qué los contrastes internos del sector agrícola son "exagerados" respecto al mismo. Y particularmente en relación a esto último, por qué razones dicho proceso, no obstante llevar dentro la Reforma Agraria que aún con el retroceso alemanista contiene objetivos sociales importantes, no ha sido capaz de registrar un desarrollo social consecuente al crecimiento económico alcanzado.

Lo anterior no niega el valor demostrativo que objetivamente tienen muchos de los materiales que son examinados, ni menos aún el de los análisis que, sobre todo en capitulos del Volumen II, dan cuenta de importantes aspectos de la estructura social rural. Pero atendiendo a la invitación abierta a que ya se hizo referencia, sentimos la obligación, con todo el respeto que merece el esfuerzo realizado por los autores, de expresar nuestro criterio y puntos de vista con toda honestidad.

Así, la apreciación general del estudio nos deja la impresión de una acumulación de hechos importantes y laboriosamente trabajados, pero en cierta forma reunidos fragmentariamente y sólo relacionados entre sí en forma parcial y que, por ende, sólo llegan a develar aspectos aislados del proceso histórico en cuyo desemboque aparece caracterizada la situación presente, y esto, sin que como paso previo se hayan desentrañado los principales mecanismos que condujeron a ella. Tal limitación, en nuestro juicio, se deriva de que el concepto de estructura social no es utilizado como una categoría analítica fundamental que norme o condicione el nivel analítico. Si bien se le utiliza como punto de referencia con respecto al cual se recogen materiales informativos interesantes y se formulan algunas observaciones de gran im- 
portancia, el estudio deja fuera algunas otras categorías explicativas fundamentales o enunciando otras, no lleva el análisis a sus últimas consecuencias. Un caso que ejemplifica estas afirmaciones, es que en todo el estudio no existe un apartado concerniente a la explotación campesina en su aspecto fundamental en el modo de producción capitalista, es decir, a través del trabajo asalariado, ni aún en la parte en que se estudia la estructura de clases en el medio rural, menos aún en aquella otra en que la aportación al producto agrícola es enfocada por tamaño y características de los predios, de donde cabría deducir que quienes más contribuyen a generarlo, incluyendo también a los jornaleros agrícolas, constituyen el sector más improductivo. Otro ejemplo más lo constituye la omisión de hacer un análisis sistemático de la naturaleza y carácter clasista de la institución estatal y de su responsabilidad, precisamente en este sentido, en la aplicación de la Reforma Agraria, tanto desde el punto de vista económico como de la desorganización política del sector ejidal y de la gran masa campesina $y$, en general, puesto que la agricultura no es un departamento estanco, en la marcha de los acontecimientos económicos y sociales del país. Al respecto, una cuestión de sumo interés a estudiar son las causas que determinan que en el subdesarrollo sea muy difícil para el estado conciliar, a un nivel menos exagerado de desigualdades, los intereses económicos divergentes de las clases sociales y de integrar, en planos más satisfactorios de participación política, el régimen democrático capitalista. Sin embargo, en la obra que comentamos, más que considerar al estado desde el enfoque de Ja ciencia social, parece tomársele como una institución aparte de la lucha de clases. Así, éste se mueve impulsado por los principios de la Revolución Mexicana y, para el caso concreto del sector agrícola, por los de la Reforma Agraria, mientras que fuerzas no explicadas suficientemente e inevitables errores y fallas institucionales, frustran o hacen lentos o difíciles los esfuerzos para que dichos principios sean llevados a la práctica.

En realidad, fuera de algunas alusiones aisladas o eufemísticas, no se encuentra en el estudio ningún apartado que en forma analítica, consistente y explícita, se encamine a determinar las características estructurales del modo de producción capitalista en el subdesarrollo y que permita determinar científicamente la forma específica en que sus rasgos generales se han manifestado en México y, en particular, en el sector agrícola.

¿Es posible formular un diagnóstico adecuado de lo ocurrido en México hasta llegar a las condiciones actuales del agro mexicano, si se hace abstracción de estas características estructurales en su dimensión externa e interna? $\mathrm{Ni}$ las comparaciones con modelos derivados de realidades históricas y socioeconómicas diferentes a la nucstra, ni aleja o desvía del modelo ideal construido con los principios de la Revolución Mexicana y de la Reforma Agraria ayudan mucho, y antes dificultan la comprensión de los hechos. Con respecto a esto último pareciera ser que el modelo ideal de la Reforma Agraria, tomado fundamentalmente de los principios populistas del cardenismo y de sus antecedentes zapatistas, se ha convertido en una piedra en el camino para la labor investigativa de muchos técnicos y estudiosos de las ciencias sociales en México.

A nuestro entender, resulta ocioso considerar si los hechos en su realidad evidente son resultados previstos o imprevistos por la Reforma Agraria, y tiene poca importancia, si es que tiene alguna, medir el alcance de las desviaciones que se han producido en torno a sus principios, aun de aquéllos que se encuentran plasmados jurídicamente. Pero más grave todavía es tomar por realidades lo que sólo existe formalmente desde el punto de vista legal y que muchas veces se encuentra registrado en categorías estadísticas, y aun lo ue sin estas bases constituye, asimismo, parte de sus principios ideológicos.

Unicamente en atención a las características de la estructura social y a su proceso histórico real es posible explicar, por ejemplo, por qué de los ejidatarios, en su carácter de estrato originado por la Reforma Agraria, se ha escindido un sector que, independientemente a su carácter como tal, ha pasado a formar parte de los empresarios agrícolas capitalistas que sustraen el control de la tierra a otros ejidatarios desfavorecidos y que explotan trabajo asalariado, quienes además, han escapado a la subordinación del crédito oficial y, en cierta manera, a la organización política desde arriba. Y por qué del mismo estrato ejidal se han separado otros sectores más, uno de los cuales, también en ausencia de su clasificación legal y estadística, pierde o cede el control de su derecho de tenencia y se integra a otro tipo de relaciones de trabajo. Neolatifundismo y minifundismo - privado o ejidal-, como polos opuestos y complementarios, responden a igual referencia por más que no sean resultados previstos por la Reforma Agraria, y explicación como ésta debe buscarse al constatar que el número de los verdaderos pequeños propietarios se detiene y aún retrocede. Iguales fuerzas estructurales, ajenas a propósitos, principios y formulismos, producen el caso del gran empresario que sin poseer tierra, pero sí recursos de capital, tecnología y relaciones financieras y comerciales, atrae hacia el mercado, mediante arrendamiento, la tierra retirada de él legalmente para los ejidos, y que reincorpora al mercado de trabajo a aquéllos a quienes el régimen ejidal suponía substraer del mismo. Bajo similar perspectiva debe analizarse el vo- 
lumen desorbitado de la sobrepoblación relativa que, no a causa del incremento demográfico, sino de la creciente concentración de la riqueza agrícola y no agrícola, de la forma en que se desperdicia parte del excedente económico y de la inadecuada manera en que el resto se invierte, aparte del monto de él que se canaliza hacia el extranjero, no encuentra ocupación productiva en éste ni en otros sectores de actividad. Sin olvidar, por otra parte, la proliferación de diversos estratos parasitarios que a distintos niveles succionan el ingreso generado por los trabajadores del sector agropecuario. Tampoco es ajeno a este contexto el hecho de que muchas medidas de política pública que en lo social y en lo económico se orientan a resolver problemas sociales, finalmente sean sacadas de sus cauces y pasen a beneficiar no a las masas populares, sino a los cortos estratos privilegiados de la población.

Puede afirmarse que en realidad, las condiciones de extrema pobreza y desorganización política que ostentan los grupos más amplios del campo, son los que definen la verdadera ubicación del sector agrícola en el país, cuyo desenvolvimiento se ha dado en beneficio de una burguesía rural próspera y de los demás sectores de actividad, sobre todo de la que constituye los estratos más altos. De una burguesía oligárquica, cabe subrayarlo, que paga tributo a aquella otra que se ubica en escaños más altos en la órbita del capitalismo mundial.

Cómo afirmar entonces que la agricultura ha cumplido con creces su papel en el proceso de desarrollo, si el proceso productivo mismo lejos de asegurar la constante mejoría de la población rural ha sido la negación viva de la consecución de los objetivos sociales básicos? (tomo III, p. XIV-100).

En nuestro criterio, la política social en su acepción cabal, esto es, como parte y como resultado del propio proceso productivo, se evalúa fundamentalmente a través de la obtención de un desarrollo social correspondiente al nivel de crecimiento económico alcanzado. Sin defecto de que, además, sea evaluado el acceso de la población a las ramas de servicios colectivos en que en su acepción más estrecha y convencional es entendida la política social, por jemplo, educación, salud pública y servicios médicos, seguridad social, etc. Sin embargo, ni en éste ni en aquel sentido, ni en ambos tomados conjuntamente, la gran masa de la población rural mexicana registra avances realmente importantes. (Véanse referencias recogidas por Silvia Millán).

En particular en el capítulo XIII del volumen III, se consideran algunos aspectos que más específicamente pueden considerarse como pertenecientes a la política social en su acepción más restringida. De entre las distintas políticas complementarias que allí se mencionan, quizá el caso más expresivo en este sentido lo constituyen los Programa de Desarrollo de la Comunidad Rural; si bien como ocurre con todos ellos, tienen una composición socioeconómica, sólo que para unas y otras varía la proporción de los ingredientes. Sin la intención de caer en la repetición de las características específicas de los distintos programas en su organización institucional, sólo expresaremos, a grandes rasgos, algunos comentarios al respecto. En lo general, estos programas se orientan a atenuar la situación de atraso y miseria que afectan a los grupos mayoritarios de la población campesina, esto es, a aliviar un poco los efectos del tipo de crecimiento seguido, por lo que en buena parte tratan de introducir mejorías en la población que no ha sido posible lograr a través del proceso productivo. En lo común, su aportación es modesta, pues como lo señalan los autores para todos los casos, lo recursos técnicos, pecuniarios y humanos son escasos; así, constituyen meros paliativos para una situación que no es posible modificar mediante instrumentos de este tipo. Aunque dichos investigadores indican que únicamente se proponen describir estas políticas, cabría insistir, a manera de sugerencia, en la interpretación analítica de ellas. Una lucubración que se nos ocurre que podría ser interesante, es en torno a la consideración de si las distintas medidas de política social, incluso aquellas que en principio pudieran estimarse como válidas universalmente - salud, alimentos y nutrición, educación y capacitaciones para el trabajo, etc.-, pueden ser consderadas haciendo abstracción del sistema económico, político y social en que funcionan, pues en última instancia éste determina el sentido final que adoptan. Así, para el caso de la realidad mexicana, ¿son proporcionales los recursos aplicados a este tipo de problemas en relación al monto de ingresos generados por esta población, que es succionado por otros estratos a través de distintos mecanismos de explotación? ¿ cuántas y cuáles medidas de esta naturaleza no serían necesarias de poder lograrse un desarrollo social a través del proceso económico mismo, o habrían resuelto los problemas que las motivan rápidamente en lugar de prolongarse años y años sin lograr superarlos? ¿cuál es el sentido final de la ayuda que estas medidas prestan para mantener la estabilidad política en el marco de la situación existente?

Quizá éstas, como otras tantas medidas complementarias que a la postre arrojan resultados insignificantes, presten su mayor contribución no en beneficio de la población rural más pobre, sino para el sostenimiento de una burocracia hipertrofiada que arrastra el proceso productivo como un peso muerto, misma que, sin olvidar excepciones, aumenta innecesariamente el costo de distintos aspectos que representan subsidios y otras ayudas para los llamados estratos marginales. 
Aunque desde distintas perspectivas, algo semejante podría decirse de mecanismos que, como en el caso de la Regulación de los Precios de los Productos Agrícolas, absorben recursos destinados a fines colectivos, pero que finalmente vienen a beneficiar de modo principal a los estratos más favorecidos, así como de diversos organismos que en lo económico y lo social atienden problemas del sector ejidal y, en general, del campesinado de bajos recursos.

Para concluir este apartado cabe formular las siguientes cuestiones: ¿hasta qué punto los intereses sociales pueden ser colocados como una meta de primer orden cuando la tendencia y el comportamiento del capital privado se orienta hacia la obtención de máximas utilidades? ¿ Puede la política pública superar la orientación de las relaciones sociales de producción prevalecientes, o en realidad sólo es susceptible de producir ciertas modificaciones en las características de la población que resultan útiles para el sistema? En el subdesarrollo, todavía la obtención de estos ajustes resulta en extremo problemática, pero aún en ausencia de cambios estructurales profundos existen posibilidades más o menos ambiciosas en atención al juego de las fuerzas actuantes, aspecto en que la organización de los trabajadores asalariados y también de los pequeños productores tiene un lugar de primera línea. Al respecto, es fundamental intentar sacar la política social, en su acepción más amplia, del marco burocrático y asistencial en que opera a través de subsidios, ayudas, estímulos, etc., y llevarla a los mal llamados estratos marginales, para integrarla en la mayor medida que sea posible en el marco del proceso productivo, sin defecto, claro está, de que se expandan las ramas de servicios colectivos destinados a fines específicos. Condición clave para que esto ocurra, es la organización no subordinada de las grandes masas de productores directos, que no mediante presiones eventuales y desarticuladas, sino como resultado de una acción vigorosa y congruente, estén en posibilidad de defender sus intereses económicos. Sólo por este medio será posible rescatar en parte la política económica y social del estrecho marco de decisiones impuestas desde arriba, para integrarla en forma tal que la participación activa de los sectores populares sea un hecho a través de su influencia real en las decisiones políticas.

En fin, en nuestra modesta opinión, el planteamiento de una política social en este sentido, aun dentro de las posibilidades presentes, exige un diagnóstico verdaderamente estructural de la problemática a que se aboca, objetivo que sólo en muy pequeña parte se logra en el estudio que examinamos.

\section{Acerca de las nuevas politicas propuestas}

Si un mavor nivel en el bienestar humano y en otros aspectos del desarrollo social no han sido factores concomitantes al crecimiento económico, pero constituyen requisitos para su continuidad y fortalecimiento o, dicho en otra forma, su ausencia sé presenta como un obstáculo para el mismo, es evidente la necesidad de intentar producirlos a través de diversas medidas.

Con todo, una cosa es la eficacia de las políticas propuestas en atención a alternativas viables en las circunstancias tomadas como hecho dados, y otra colocar los objetivos sociales en un primer plano considerando los cambios estructurales profundos que ello presupone.

En el primer caso, más que otra cosa la orientación central es ajustar las características sociales a las necesidades de un sistema que no tiene por finalidad las necesidades de la sociedad como un todo, sino fundamentalmente los de la empresa privada y la obtención de utilidades, pero que para su desenvolvimiento en planos superiores requiere, entre otros tantos, de requisitos peculiares en la masa humana. Sin olvidar excepciones en puntos de vista particulares, pues como ya se dijo en la obra aludida se advierten ciertas discrepancias de criterio entre algunos investigadores, cabe aventurar que en su orientación general el tratamiento que se da al tema es en el sentido que acabamos de decir. Así, por ejemplo, la expansión del empleo productivo tanto en el propio campo como en los restantes sectores de actividad, v la más equitativa distribución del ingreso, se plantean en términos de cambios en la composición de la oferta y la demanda de bienes y servicios, de estímulos para la inversión privada, etcétera, añadiéndose como fundamento importante para proveer a estos ajustes, que de no modificarse las actuales características del mercado interno, el empresario estará quizá en posibilidades de continuar obteniendo utilidades tan altas como hasta ahora, pero que cada vez tendrá menores oportunidades para reinvertir, (tomo III, p. XIV31). El señalamiento de la miseria de los muchos y su creciente aumento, es considerada en diversos lugares, más en relación a su carácter de amenaza para la estabilidad política del sistema, que en su sig. nificado social, pues el tipo de crecimiento económico seguido se justifica en atención a necesidades planteadas, en fases anteriores, en términos de exigencias de capitalización y de incrementos en la oferta. Puesto que al presente el problema se ha invertido y ahora los requerimientos son de demanda — se dice-, hay que influir sobre los mecanismos que propician su expansión. En esta forma los excedentes agrícolas previstos hallarán salida en el mercado y podrá lo- 
grarse la expansión y redistribución de la industria. ${ }^{2}$ La empresa industrial, podrá apoyarse en el mercado interno para eludir su actual incapacidad para salir competitivamente al exterior, ya que esta coyuntura le permitirá producir a escala, abatir costos y elevar sus normas de calidad y, así, proyectarse hacia el mercado internacional. (tomo II, pp. XIV-29-30). Todo esto, desde otra perspectiva, requiere que la fuerza de trabajo tenga mayores niveles de educación general y de formación y calificaciones para el trabajo, y a fin de que pueda intervenir en los mecanismos que determinan la mejor distribución del ingreso, es preciso que tenga una mejor organización, es decir, que también como parte de las readaptaciones a un nivel productive superior, es necesario que se produzcan avances en el régimen democrático capitalista. La preservación de lo esencial del sistema impone, asimismo, el sacrificio de ciertos sectores, por ejemplo, de entre los neolatifundistas y del sector de intermediarios, al par que se otorga una decidida atención a los estratos más amplios y miserables. atención que debe consistir principalmente en mejorar sus condiciones productivas para impedir que la inversión pública, como ya está ocurriendo, se desvíe de la actividad económica hacia la asistencial, que sólo transitoriamente produce efectos en una situación que va en crescendo (tomo III, pp. XIV-30-31). Dadas las tendencias y comportaniento de la inversión privada, la inversión pública debe manejarse en el sentido de estimular la acción de aquella para lograr las condiciones a que antes se ha hecho referencia (tomo IV, pp. XIV11-12). En tal contexto, corresponde al estado alcanzar una mayor eficacia burocrática e institucional, continuar contribuyendo a la creación de infraestructuras económicas y dar un peso especial a los objetivos del empleo y a otras acciones de ajuste necesarias para impedir que el ingreso agrícola se deteriore, por ejemplo, eliminando intermediarios mediante una mayor participación en los canales de comercialización. (tomo III, p. XIV-16).

Esta forma de plantear las cosas no excluye, obviamente, las intenciones y posibilidades reales de introducir mejorías en los aspectos sociales, pues precisamente se trata de conseguir en ellos adecuaciones acordes a las exigencias del aparato económico. Empero, independientemente de las dificultades que se presentan en el subdesarrollo para el eficaz funcionamiento de estos mecanismos tecnocrático-desarrollistas, es evidente que consciente o inconscientemente implican en última instancia la subordinación de los objetivos sociales a los de la

${ }^{2}$ Véase, por ejemplo, tomo III, pp. XIV-10, XIV-14, XIV-21, XIV-24, etcétera... empresa privada, la cual, por otra parte, está representada en buena proporción por los monopolios extranjeros. Así, suponiendo sin conceder que se logren comportamientos satisfactorios en las variables sociales, esto no implica cambios estructurales, sino llevar la explotación del trabajo a los planos de una economía más evolucionada en la que, consecuentemente, puede darse una mayor participación de la población en la producción y en el consumo de bienes y servicios. Con todo, procede subrayarlo, esto no tiene nada que ver con la justicia social en la verdadera acepción del término, es decir, con la organización racional de la sociedad en la que los intereses colectivos normen la activídad económica y el proceso social global, y no al contrario. Empero, esto no es posible en el capitalismo que por su propia naturaleza implica la concentración de la riqueza social en unas cuantas manos y la conducción de la política económica y social, en sus elementos fundamentales, en torno a los intereses privados de quienes poseen o controlan los medios de producción, independientemente, por otro lado, del nivel en que se exprese dicha desigualdad.

Un elemento que en nuestra opinión sería de gran interés tratar en la citada obra, es el concerniente a la manera como en nuestro medio es frecuente tomar como medidas de política social, acciones que, basadas únicamente en razones políticas se traducen en concesiones populares. Las cuales, por cierto, en buena proporción resultan anárquicas y muy poco afortunadas para el proceso económico y social en su conjunto y para el de los supuestos beneficiarios directos.

En el estudio hay diversas referencias y alusiones a este tipo de fenómenos, pero sería muy útil reunirlas y analizarlas en su conjunto. Renglones concernientes a las necesidades del estado de exhibir neutralidad clasista en su carácter de gobiernos "emanados de la Revolución", o de sostener los principios de la unidad nacional y, muy principalmente de exigencias para mantener la estabilidad política, han determinado que los objetivos sociales se hayan manejado dentro de un marco burocrático estrecho y en razón de conveniencias circunstanciales. Así, en el limitado marco que ofrece la ausencia de un verdadero régimen democrático, se toman frecuentemente como medidas con orientación social lo que sólo constituye respuestas a presiones populares desorganizadas o a necesidades de momento, que en realidad no tienen por finalidad resolver a fondo problemas colectivos, sino satisfacer ciertos intereses políticos en el sentido más estrecho del término. Sería de gran interés examinar cómo este fenómeno se ha caracterizado por la intromisión de concesiones sociales dentro de la política económica que, sin que aquéllas lleguen a tener un alcance significativo, han perjudicado la eficiencia productiva, ya que por los 
motivos señalados no responden a ningún plan ni propósito definido, ni a criterios técnicos, sino a la necesidad de calmar la inquietud de determinados sectores de la población, de ofrecer a los estratos más pauperizados un mínimo de expectativas o para buscar su apovo en las campañas electorales. De esta manera, muchas medidas que sobre bases más sólidas podrían haber dado resultados más o menos satisfactorios, han derivado en despilfarro de esfuerzos y recursos y en situaciones viciosas que, una vez creadas, por las mismas razones que las produjeron, luego son muy dificiles de romper. Entre otros tantos ejemplos, son ilustrativos sobre el particular, la justificación de entrega de tierras sin la selección adecuada de candidatos, la creación. de la categoría de campesinos sin tierra, pero con derechos a salvo y la dotación de superficies inadecuadas en tamaño o sin la calidad necesaria para su aprovechamiento; pueden considerarse también en este sentido muchos aspectos de la política de colonización en sus lineamientos durante el régimen de López Mateos, y, asimismo, la forma en que se ha manejado el crédito ejidal, etcétera.

Con respecto a esto último, como lo hacen notar los autores, de unos años acá el Banco Ejidal ha tenido que efectuar una serie de labores que no le correspondería cubrir:

A falta de una institución adecuada, se le ha utilizado como canal de subsidio a sectores agrícolas marginales o a regiones deprimidas, cuya solución no la puede dar una institución de crédito agrícola, pues su campo de acción es necesariamente limitado. Muchas veces se le ha manejado más con criterios políticos que con criterios financieros, aduciendo su "orientación social". Si bien se le han dado las funciones de un banco de fomento que debe canalizar su acción hacia el desarrollo de sectores económicamente débiles, éste no ha podido desarrollar el instrumental y los métodos necesarios para actuar como tal. Su operación se ha basado fundamentalmente en el otorgamiento de créditos de avío, que al nivel de pequeños agricultores pierden su carácter promotor y se convierten en créditos de sostenimiento. Los créditos a mediano y largo plazo, que podrían ser la base de la capitalización y desarrollo del sector por él atendido, han representado una porción minoritaria de su acción crediticia. (tomo III, p. XIV-76, cursivas nuestras).

Como se dice más adelante:

Dentro del aparato gubernamental ligado a la reforma agraria, era el único que podía haber actuado como elemento de pro- moción de la institución ejidal, $y$ en esto sus resultados han sido muy modestos. (tomo III, p. XIV-78, cursivas nuestras).

Con todo, y aun cuando consideran que deben buscarse mejores caminos que el crediticio para subsidiar este tipo de agricultura, estiman que esta función no ha sido del todo negativa, ya que no puede considerarse como una pérdida neta para el sistema económico,

...pues si bien [tales erogaciones] no vuelven a las cajas del Banco, ni directamente a las arcas del Gobierno, el efecto multiplicador que sobre la actividad económica crea el producto agrícola logrado por estos recursos, el aumento en su capacidad de compra que estos créditos generan en un amplio estrato de la población, etc., seguramente rinden dividendos económicos mayores para el sistema que los recursos que en esta política se emplean. (tomo III, p. XIV-78).

Sin embargo, los mecanismos que determinan el deterioro del ingreso campesino, que son examinados desde diversos ángulos por los autores, permiten deducir que tales recursos, independientemente de que contituyan una mayor o menor pérdida para el sistema, han significado ínfimos beneficios para este tipo de agricultores y que lo realmente grave es que no hayan cumplido su objetivo de promover el desarrollo económico a nivel satisfactorio.

¿Qué ocurre por el contrario, con el crédito agrícola privado?:

Debido a la tendencia del aparato financiero privado de operar créditos cuantiosos a los grandes productores, estas diferencias en crecimiento indican una atención financiera a los grandes productores muy superior a la que reciben los medianos y pequeños productores. Esto naturalmente conduce a mantener y agravar el desarrollo polarizado de la agicultura nacional, con los consiguientes efectos negativos sobre la distribución del ingreso y la demanda interna. Si bien es dificil esperar que la banca privada cambie sus métodos, aun asi cumple ya una función fundamental al apoyar una parte importante del financiamiento a la producción agricola. (tomo III, p. XIV-82, cursivas nuestras).

¿Para quiénes y para cuántos se cumple esta importante función, si como se afirma, esta "tendencia" conduce a mantener el desarrollo polarizado de la agricultura que es, precisamente, la negación de los objetivos sociales que debían derivarse del propio proceso productivo? 
Por lo pronto, y en concordancia a esta manera de ver las cosas, se recomienda que dadas las características de la estructura agraria en México, la banca privada atienda en forma directa y exclusiva a los medianos y grandes agricultores que aportan cerca del $70 \%$ de la producción agrícola total. (tomo III, p. XIV-88). Y que por otro lado, la banca oficial sirva a los productores medianos y pequeños con capacidad de crédito, presente y futura independientemente $a$ formas de tenencia de la tierra, en tanto que los problemas de los productores llamados marginales - que representan más del $50 \%$ del total de ellos-, sean atendidos por una institución de desarrollo rural. (tomo III, pp. XIV-88-84-89).

Este, se asevera, “. . . sería un esquema sano de financiamiento del desarrollo del sector agrícola". (tomo III, p. XIV-89). Cabe hacer notar que en este contexto, como en muchas otras partes del trabajo, aparece registrado similar respeto por los "métodos de operar" del sector privado, así en su rama empresarial agrícola, como financiera, industrial, etcétera.

En principio, las medidas consideradas para la institución de desarrollo rural que propone y que comprenden "...educación, asistencia técnica y uso masivo de mano de obra para crear empleo y generar ingreso". (tomo III, p. XIV-86), podrían considerarse muy útiles para introducir mejorías en la situación prevaleciente. Empero, cabe hacer algunas consideraciones sobre el alcance de estas medidas y sobre la mayor o menor rapidez con que podrían obtenerse resultados a través de ellas.

Las mayores disponibilidades de asistencia técnica y las más grandes oportunidades de empleo que su acción crearía, harían de momento innecesario el establecimiento de un costoso programa de crédito a los pequeños productores, pues los propios ingresos adicionales ayudarían a financiar los magros gastos de cultivo de las reducidas explotaciones de subsistencia, como ya acontece en algunos de estos productores. En caso contrario, podrían organizarse pequeñas cooperativas de crédito, cuyos recursos serían aportados y contratados en relación a los distintos programas de utilización de mano de obra que operaran en la región. (tomo III, p. XIV-86, cursivas nuestras).

Los correspondientes programas, integrados regionalmente y como parte de un plan nacional, comprenderían, además de lo concerniente a organización y producción agrícola, una gran variedad de renglones relativos a la expansión ocupacional y a la mejoría del ingreso; construcción de obras de captación de agua, de caminos, de almacenes, de urbanización y habitación, así como la creación de pequeñas industrias, desarrollos turísticos... Como se hace ver "Parte de la participación de la mano de obra podría ser pagada en especie: alimentos, ropa, utensilios, mobiliario, herramienta, etc. (tomo III, p. XIV-87). Y lo que es todavía mejor:

Esta forma de pago permitiría movilizar excedentes agrícolas o satisfactores industriales hacia estas zonas, o la producción de artículos como parte de la política de creación de empleo. Estos productos no representarían un subsidio, sino un gasto de inversión que, al mismo tiempo de beneficiar estas zonas, crearían una demanda controlada por productos excedentes de obra hacia otras zonas. (tomo III, pp. XIV-87-88).

A través de esta institución sería posible, asimismo aplicar progragramas masivos de alfabetización y calificaciones para el trabajo con demanda local o para proveer a la migración productiva de mano de obra hacia otras zonas. (tomo III, pp. XIV-87-88).

Un elemento de primera línea en el proyecto es lograr la organización de los productores - agricultores, artesanos, comerciantesy una vez alcanzado esta meta "... se buscaría canalizar el financiamiento hacia tales grupos". (tomo III, p. XIV-87).

Sobre lo hasta aquí expresado, estamos de acuerdo con los autores en que ha sido equivocada la política de sobrecargar a las instituciones crediticias oficiales con una serie de funciones de desarrollo económico y social, que han implicado que se llegue al "... subsidio bajo la forma de crédito, incurriéndose en fuertes pérdidas y sin beneficios ostensibles para los recipientes de estas acciones". (tomo III, p. XIV-85). Así como con su convicción de que estos renglones deben ser abordados a través de medidas globales y mediante políticas de desarrollo regional. Empero, se nos plantea la duda de que estas medidas, que confieren un tratamiento especial a más del $50 \%$ de los productores agrícclas, que como se afirma "... no son sujetos de una política normal de crédito agrícola", (tomo III, p. XIV-86), constituyan los instrumentos más rápidos y eficaces para alcanzar metas importantes.

Aunque la institución de desarrollo social rural, según las recomendaciones de los autores debería funcionar en un contexto de políticas globales encaminadas a lograr un mayor y más igualitario desenvolvimiento del sector agrícola, en su conjunto; como por ejemplo in- 
virtiendo las tendencias de transferencia de recursos de éste a otros sectores de actividad, robusteciendo los canales crediticios, procurando una distribución más equitativa de la asistencia técnica de la investigación agrícola y de la tecnología, favoreciendo la democratización en la tenencia de la tierra, fortaleciendo el régimen ejidal; el tratamiento que se indica para la agricultura deprimida, en sus implicaciones inmediatas, no parece exceder con mucho el marco económicoasistencial en que ha venido operando.

Representa un avance, es cierto, su ubicación en una institución que permita organizar y coordinar esfuerzos, jerarquizar necesidades y proveer al aprovechamiento óptimo de los recursos, pero de antemano el plan queda condicionado a muchos factores limitantes que si bien implican por lo pronto bajos costos, también presuponen lentitud en la obtención de resultados. Muy significativo es el lugar que se les concede en el sistema crediticio, relacionado por cierto a lo que se sugiere en otra parte del estudio para atender, desde este ángulo, a los productores más pobres y con resultados inciertos en sus explotaciones. Una solución al respecto sería, según se expresa, que “. . . una institución que no se llamaría banco les concediera préstamos como una labor de asistencia... (tomo III, p. XIII-39, cursivas nuestras). La normalización de estos productores como sujetos de crédito queda así subordinada en buena parte al autofinanciamiento del programa a través de su propia mano mano de obra, a la medida en que vayan logrando ingresos adicionales y bases organizativas más adecuadas, a la vez que se crean salidas hacia otras actividades en la región y hacia otras zonas.

No se trata de negar que haya objetivos sociales en estas medidas, pero sí es preciso insistir sobre las limitadas perspectivas de su alcance y sobre su extrema subordinación a exigencias del sistema económico, político y social. Este tratamiento especial a los estratos más pobres del medio rural, que enfatiza en el bajo costo del programa, si bien no ofrece perspectivas substanciales para la rápida y eficaz solución de la problemática a que se aboca, en cambio es susceptible, sin demandar cuantiosas inversiones, de realizar ciertos ajustes necesarios para el sistema. Así, por ejemplo, fijar por un tiempo la mano de obra a los medios rurales atenuando los factores expulsivos del campo en tanto que se desenvuelvan otros sectores, al par que se estimula este proceso mediante leves aumentos en el poder adquisitivo de estas masas campesinas y se influye sobre ellas de modo de crear fuentes humanas de economías externas más satisfactorias.

Como en alguna parte se afirma, la situación prevaleciente en el agro mexicano requiere, para la solución de su problemática, de po- líticas con valor económico y con alto contenido social. El examen del valor económico de estas políticas es hecho en otros de los trabajos aquí incluidos, y sobre el contenido social de los mismos, pues no se niega que los tengan, puede decirse por lo pronto que es magro, como los recursos adicionales que se preven a corto plazo, para los beneficiarios. A nuestro modo de ver, el tratamiento que se hace de las variables sociales no es en atención a los intereses de las masas populares, sino en cuanto a su significado para un proceso de desarrollo regido por los intereses privados de unos cuantos, nacionales y extranjeros, que concentran en sus manos la riqueza económica y el poder político. Las variables económicas y sociales fundamentales que cabría controlar, quedan fuera de tal perspectiva, como necesariamente tiene que ser en una sociedad productiva y, por ende, del proceso de desarrollo social. 